\title{
An Analysis of Interrelation between Current Environment and Socioeconomic Status Regarding Water Pollution in Turkish Black Sea Basin
}

\author{
Suleyman UlgeR* and Yoshiro Higano
}

\begin{abstract}
In this paper, current environment related socioeconomic state in Turkish Black Sea Basin is analyzed by using a conceptual mathematical model clarifying the interaction between socioeconomic activities and contribution of pollutants such as BOD, COD TSS, TN and TP by industrial, agricultural and other land use/land cover activities and future trends. Furthermore, we run the model dynamically from 1998 to 2009 by the specification of all sectors into 27 categories in each zone in the basin. Then we analyze the role of existing socioeconomic state the point of view in reducing the contaminants discharged into the Black Sea.
\end{abstract}

\section{Introduction}

The Black Sea is known as one of the semi-closed seas mainly deteriorated by human activities. According to Black Sea Environmental Program (BSEP) [3], Global Environmental Facility (GEF) [7] the Black Sea has suffered from catastrophic degradations of its natural resources. The entire ecosystem starts to collapse due to increasing loads of nutrients from agricultural activities, domestic and industrial sources located along the Black Sea coastal line, and/or contaminants transferred by rivers and streams to the sea. This problem coupled with an unmanaged irrational exploitation of fish stocks caused a sharp decline of fisheries resources [6].

There are many studies have been carried out to address the water pollution issues. However, the deterioration of water quality is still critical issue. The Black Sea Basin and its socioeconomic structures have been reviewed including hydrological and ecological properties from the point of view referring some researches in the previous paper [24] shows that the Black Sea Basin has different ecosystem and economic characteristics since many countries located in the basin and coastal area of the sea. Therefore, a unique policy would not be sufficient for the Black Sea countries to address the problem. The contaminants particularly nutrients discharge to the sea directly by activities located coastline and indirectly carried by the rivers. Here, it is known the main sources of direct discharges along the Black Sea coast and the cost of treatment for each coastal country, although financial sources are not clear [6]. However, it is unknown the sources of pollutants carried by the rivers, which include almost more than $90 \%$ of total pollution in the entire basin [6]. Therefore, we emphasize that each sub-basin in the Black Sea Basin should be studied in formulating its economic structure integrated with environmental media to find out the

* Ph.D. Student, Institute of Agricultural and Forest Engineering, University of Tsukuba

Ph.D. Professor, Institute of Agricultural and Forest Engineering, University of Tsukuba 
sources of pollutants, their contributions, and interrelations in order to implement any instrument on progressing the water quality in the Black Sea.

In this paper, from the point of view and the approach referring the previous paper [24], we have developed a mathematical model clarifies and integrates the current environment and economic activities in the Turkish Black Sea Basin which is one of the important subbasin of the Black Sea. Furthermore, we run the model from 1998 to 2009 and have analyzed sources of pollutants, their contributions related economic indicators in each zone in the basin so as to evaluate how the current policy impact on the water pollution and future changes. Finally, we propose some policy instrument to improve the water quality in the Turkish Black Sea Basin

\section{The Model}

The skeleton of the model and completed flowchart of the two systems are shown in Figure 1. Here, first we specify the model according to environmental and economic state and their interaction systematically formulated into equations then we run the model within the simulation period.

\subsection{Objectives of Modeling}

The objectives of the modeling of the two systems summarized as follows;

1. Clarifying the multi-sector interrelationships and to determine the characteristic of ecosystem and socioeconomic structure in each zone.

2. Estimation of distribution of the pollutants in activities such as domestic, industrial particularly manufacturing, agriculture, fishery, livestock, and other land use/land cover activities.

3. The pollutants generated from each sector converted into economic terms in order to analyze how production activities affect the environmental states or vice versa, and future changes.

4. Maximizing the production activities such as level of output measures in GRP as a concept, which is related market flow condition such as capital output ratio, investment etc. with introducing various environmental instruments into the model and run the model to find out optimum solution sets considering sustainable economic growth with less harm to environment as water quality objectives.

\subsection{Methodology of Modeling}

In the light of objectives mentioned above, we have developed a conceptual mathematical model into linear programming system considering the existing environmental and economic state in the Turkish Black Sea Basin. The methodology of modeling is based on the relations mainly with macroeconomic indicators such as production, investment, input, and output into the market flow system and land use activities to the amount of pollution, which released to environment by the process of sectors in the basin system [8], [9], [24]. Second, the model developed using the data available including macroeconomic indicators and environmental properties that some of them mentioned above gathered by the Turkish governmental organizations. These are mainly State Institute of Statistic (SIS) [20], [21], 


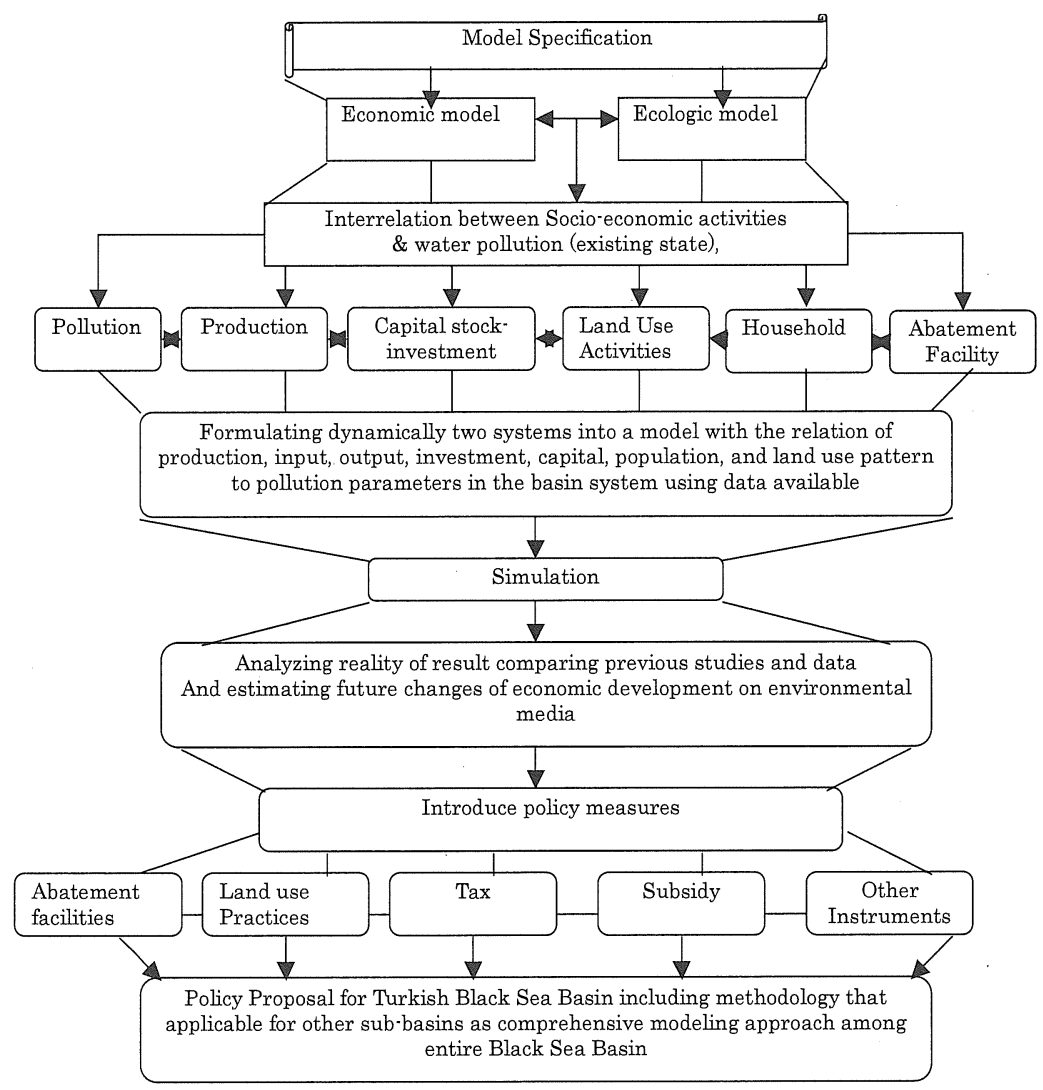

Figure 1 The Flowchart of the Model

[22], [23], State Planning Organization (SPO), [18], [19], State Hydraulic Works (SHW) [17], and Electrical Power Resources Survey Administration [11] describing the economic structure and indicators related to water pollution. Finally, we formulate and integrate whole indicators including some assumptions and factors into mathematical equations in zones in the Turkish Black Sea Basin. The model includes two sub model connected each other with relation of pollution parameters, production indicators and factors described as follows :

In the study area there are six zones

Study area covers Turkish Black Sea Basin [17], [21] is classified and divided into sub basins (zones) according to watersheds, hydrology and geological structure. For more information, see the reference [21].

$$
Z=\text { zone } 1,2,3,4,5,6
$$

Total pollution is sum of the total pollution generated from the whole basin:

It is necessary to clarify each equation in detail in order to get whole picture between economic indicators, variables, and pollution parameters.

$$
T P B_{p}(t)=\sum_{z} T P_{z p}(t)
$$


where, $T P B_{p}(t)$ is total amount of pollutant $p$ generated from the Turkish Black Sea Basin at time $t, T P_{z p}(t)$ is total amount of pollutant $\mathrm{p}$ generated in each zone $z$.

$$
p=\mathrm{BOD}, \mathrm{COD}, \mathrm{TSS}, \mathrm{TN}, \mathrm{TP}
$$

Pollution generate from each zone

$$
T P_{z p}(t)=P H_{z p}(t)+P I_{z p}(t)+P L_{z p}(t)
$$

Where, $P H_{z p}(t)$ is an amount of pollutant $p$ generated from domestic wastewater, $P I_{z p}(t)$ is amount of pollutant generated from industrial wastewater and $P L_{z p}(t)$ is amount of pollutant from land use.

Pollution from household:

$$
P H_{z p}(t)=\sum_{k} e_{k p}^{h} P T_{z k}(t)
$$

Where, $e_{k p}^{h}$ is an amount of pollutant per capita for each type of settlement $k . k=1$ village no treatment, $k=2$ without sewerage, $k=3$ with sewerage, $k=4$ primary treatment and $k=$ 5 is activated sludge. $P T_{z k}(t)$ is population with settlement type $k$. Here, $k 1, k 2$ and $k 3$ has no treatment facility. However, amount of pollutant per capita is different because, the settlement type is different in each category. Furthermore, village population do not receive any treatment as a current state in the basin

Population :

Since the treatment plants are recently established in some cities and towns, the capacity of these plants cover the increase of population in those settlements for more than 20 years [14], [19]. The following equation shows the total population in each zone:

$$
P_{z}(t)=\sum_{k} P T_{z k}(t), \text { and } P_{z}(t+1)=\left(1+\eta_{z}\right) \sum_{k} P T_{z k}(t) \pm \Delta P_{z k}(t)
$$

where $\eta_{z}$ is growth rate of each zone $z, P_{z}(t)$ is total population in each zone and $\Delta P_{z k}(t)$ is change of population regarding treatment. It increases for biological-treated population and decreases for others. Here some people from $k 2$ to $k 4$ receive biological treatment in each year so those numbers of people are added to $k 5$ as total treated population. It also means those treated people reduce the total untreated population. In Turkey, the government transfers annually a certain percentage of its revenue to support the budget of municipalities [22]. Municipalities with government support establish investments for household treatment. According to available data, we assume the investment for household treatment in each zone is a part of total investment because of the difficulty in expressing the budget balance for each municipality mentioning that in the study area, there are more than 500 municipalities and each one has its own budget. Hence the capital accumulated for household treatment is :

$$
K T_{-} H_{z}(t+1)=\left(1-\sigma^{T}\right) K T_{-} H_{z}(t)+I T_{-} H_{z}(t)
$$

where, $K T_{-} H_{z}(t)$ is capital stock for abatement type $k$ in zone $z, I T_{-} H_{z}(t)$ is an annual investment for abatement $k$ in zone $z$. The treated population will increase as many as there is investment for it to reach the final target all population served with sewerage system and biological treatment. Therefore, the total treated population by abatement type $k$ is dependant on the investment as expressed in following equation: 


$$
I T_{-} H_{z}(t)=\sum_{k} \beta_{k} \Delta P_{z k}(t)
$$

where, $\beta_{k}$ is cost per capita including maintenance cost for each type of treatment $k$ in order to have biological treatment. This investment is also a part of total investment in each zone :

$$
I T \_H_{z}(t)=\varepsilon_{z}^{h} I_{z}(t)
$$

where, $\varepsilon_{z}^{h}$ is household-treatment investment coefficient and $I_{z}(t)$ is total investment in each zone.

Pollution from industry:

In Turkey, industrial activities are classified [22] according to International Standard of Industrial Classification (ISIC). There are 97 sectors (ISIC rev. 3). Here, we reclassified those sectors into 27 sectors in each zone in the basin is shown in Table 1.

Total pollutants generated from all industrial activities are determined with the following equation :

$$
P I_{z p}(t)=P M I_{z p}(t)+\sum_{l} e_{l p} A_{z l}(t)+e_{p}^{f} X_{z 3}(t)
$$

Table 1. Industrial classification in zones

\begin{tabular}{|c|l|}
\hline Index & \multicolumn{1}{|c|}{ industry } \\
\hline 1 & Agriculture \\
2 & Livestock \\
3 & Fisheries \\
4 & Forestry \\
5 & Food, beverage, \\
6 & Tobacco \\
7 & Textile \\
8 & Wearing, dressing, and dying \\
9 & Leather \\
10 & Wood and Wood products \\
11 & Paper and paper products \\
12 & Publishing and printing \\
13 & Coal and petroleum products \\
14 & Chemical \\
15 & Plastic and rubber \\
16 & Non-metallic mineral products \\
17 & Basic metals \\
18 & Fabricated metals \\
19 & Machineries not else where classified \\
20 & Office and accounting machineries \\
21 & Electric machines \\
22 & Communication devises \\
23 & Medical equipment \\
24 & Vehicles \\
25 & Other transport equipment \\
26 & Furniture \\
27 & Others (mining, electric, construction, service etc.) \\
& \\
\hline
\end{tabular}


where, $P M I_{z p}(t)$ is total amount of pollutant generated from manufacturing industry, $e_{l p}$ is an amount of pollutant generated from livestock $l$ per head and $A_{z l}(t)$ is number of livestock $l$. $l=1$ is cattle and $l=2$ is poultry. $\quad e_{p}^{f}$ is an amount of pollutant generate from one unite of production ( 1 billion Turkish lira) of fishery and. $X_{z 3}(t)$ is production of fishery There are five existing types of treatment plants for manufacturing sectors in each zone: these are no treatment pretreatment, chemical, biological, and advanced treatment. Here we classified the production in each zone in terms of treatment facilities.

$$
P M I_{z p}(t)=\sum_{i=5}^{27} \sum_{T} e_{i p}^{T} X_{z i}^{T}(t)
$$

where, $e_{i p}^{T}$ is an amount of pollutant emitted by one unit of production ( 1 billion $T L$ ) with treatment type $T$ for each industry $i, X_{z i}^{T}(t)$ is the production with treatment $T$ for each industry. $T=1$ is no treatment, $T=2$ : pretreatment, $T=3$ : biological treatment, $T=4$ : chemical treatment and $T=5$ is advanced treatment. According to recent environmental law, every factory has to establish a treatment plant as a part of its construction. New investments also have to establish their treatment plants according to Environmental Impact Assessment Regulation in Turkey, so all new investments have treatment plants. However, some factories already established and entered to the market have no treatment plant or treatments are not sufficient. The capital stock for those treatment facilities is expressed in this equation:

$$
K T \_I_{z T}(t)=\sum_{i=5}^{26} \gamma_{T} X_{z i}^{T}(t)
$$

where, $\gamma_{T}$ is cost of abatement type $T$ per one unit of production, $K T I_{z T}(t)$ is capital stock of industrial treatment facilities of abatement $T$.

Capital accumulation for investing in each treatment type is expressed:

$$
K T \_I_{z i T}(t+1)=\left(1-\sigma_{i}^{T}\right) K T I_{z i T}(t)+I T \_I_{z i T}(t)
$$

where, $\sigma_{i}^{T}$ is depreciation rate for treatment facilities, $I T \quad I_{z i T}(t)$ is investment for industrial treatment for industry $i$. This investment is also a part of total investment in each manufacturing industry described:

$$
I T \_I_{z i T}(t)=\varepsilon_{z}^{i} I_{z i}(t)
$$

where, $\varepsilon_{z}^{i}$ is industrial-treatment investment coefficient in each industry i for treatment type $T$ in each zone, $I_{z i}(t)$ is investment for industry.

Pollution from land use:

$$
P L_{z p}(t)=\sum_{j} e_{j} L_{i j}(t)
$$

where, $e_{j}$ is an amount of pollutant $p$ export rate per hectare for each type of land use pattern $j$. $\quad L_{z j}(t)$ is an area of land use $j$ in each zone at time $t . \quad j$ is land use index. $j=1$ is crops + area under fallow, $j=2$ is other agriculture (vegetable, vineyard, orchard, olive, tea), $j=3$ is posture, meadow and wetland, $j=4$ is forest, woodland and $j=5$ is city area (residential, industrial etc) 
Land use pattern :

$$
\begin{gathered}
L_{i j}(t+1)=L_{z j}(t) \mp \Delta L_{z j}(t) \\
\Delta L_{z 5}(t)=\theta_{z} \eta_{z} P_{z}(t)+\phi_{i} I_{z i}(t)
\end{gathered}
$$

where, $\Delta L_{z j}(t)$ is change of land use by time, $\Delta L_{z 5}(t)$ is increase of city area in each zone $z$, $\theta_{z}$ is demand of residential area per capita in zone $z$, in addition, $\phi_{i}$ is demand of investment lot per production unit for each industry $i$.

Land use category 5 might be changed for any purpose. However, The area used for agriculture and forest should not be decreased according to Turkish regulation except for fundamental investments, which may be used in converting any land if there is no other options. According to monitoring study carried by State Statistic Institute (SIS) in Turkey [23], land use change by the time is negligible. Therefore, we assumed that the area of land use is constant by the simulation period.

Relation between production and capital

$$
K_{z i}(t)=\alpha_{i} X_{z i}(t)
$$

where, $K_{z i}(t)$ is capital stock of industry $i$ in zone $z$ at time $t, X_{z i}(t)$ is total production of industry $i$ and $\alpha_{i}$ is capital required per production unit. (capital output ratio for each industry)

Capital accumulation:

$$
K_{z i}(t+1)=\left(1-\sigma_{i}\right) K_{z i}(t)+I_{z i}(t)
$$

$\sigma_{i}$ is depreciation rate, $I_{z i}(t)$ is investment calculated according to capital formation ratio for each sector as a part from total investment.

$$
I_{z i}(t)=B_{z i} I_{z}(t)
$$

where, $B_{z i}$ is capital formation matrix for each industry in each zone Flow of the market:

$$
\begin{gathered}
x_{z}(t)=\sum_{i} X_{z i}(t) \\
X_{z}(t) \geq A_{z i} \sum_{i} X_{z i}(t)+C_{z}(t)+I_{z}(t)+E x_{z}(t)-E m_{z}(t)
\end{gathered}
$$

where, $A_{z i}$ is input coefficient matrix, Exz $(t)$ is exports, $C_{z}(t)$ is consumption $E m_{z}(t)$ and is imports. Here, consumption and investment estimated including sum of private and government activities.

$$
\operatorname{GRP}_{z}(t) \leq \sum_{i} \mu_{z i} X_{z i}(t)
$$

where, $G R P_{z}(t)$ is gross regional product for Turkish Black Sea Basin, and $\mu_{z i}$ is Value added ratio

Objective function:

$$
M A X=\sum_{i}\left(\frac{1}{1+\rho}\right)^{t-1} \sum_{z} G R P_{z}(t)
$$

Subject to equation $\cdots(1)$

Objective function in the model is to maximize the GRP in each zone considering capital stocks, investments for production and treatment, consumption and other related variables 
and constrains described equations (1) to (22). subject to equation (1). It means with those variables and parameters using in the model, it can be found out how the total pollution increases or decrease by the time depending on variables and constraints that assumed as a current state in 1998 and it will continue without any external impact on economy in the study area.

\section{Simulation}

We run the model from 1998 as an initial year to 2009 and 2010 using Lingo software program $[10]$. The simulation results, analysis, and interpretations are as follows;

\subsection{Total Pollution in the Basin}

Total pollution generated from socio-economic activities demonstrated in Figure 2. Here, it states that pollutants are decreasing by the simulation period. From 1998 BOD by $22.6 \%$, COD by $21.8 \%$, TSS by $21.3 \%$, TN by $4.2 \%$, and TP by $7.2 \%$ percent decrease at the end of the year 2009. It can be also conducted that reducing of TN and TP are very less amount comparing the others because, the treatment techniques mostly do not include nutrients removal system. Distributions of pollutants and sectors' contributions are shown in Figure 3, 4, 5, 6 and 7.

Household wastewater is the biggest contributor in terms of BOD, COD, TSS, and TP in each year. In case of TN, the biggest source of pollutant is land use, which contributes more than $50 \%$. Both household and land use contribution is $80-85 \%$ of total BOD and COD, $60-65 \%$ of TSS, and $85-90 \%$ of total TN and TP.

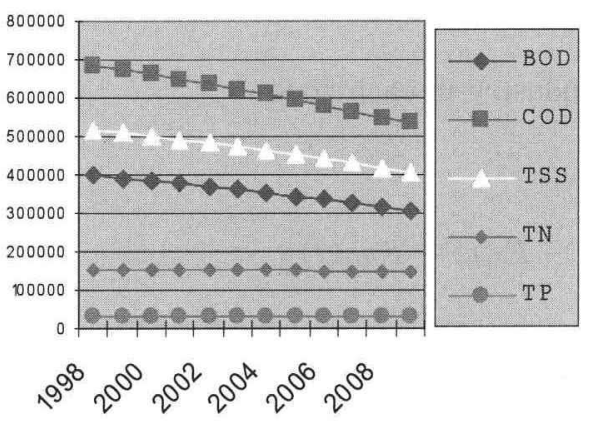

Figure 2 Total pollution in the Basin (ton)

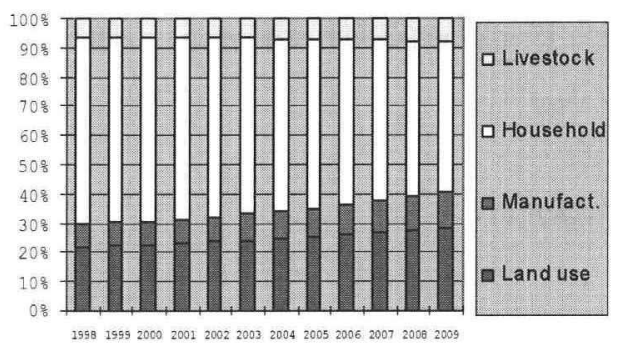

Figure 4 COD contribution by sector in the basin

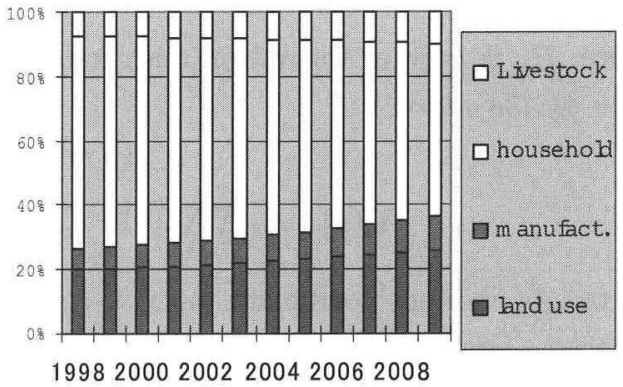

Figure 3 BOD Distribution in the Basin by sector

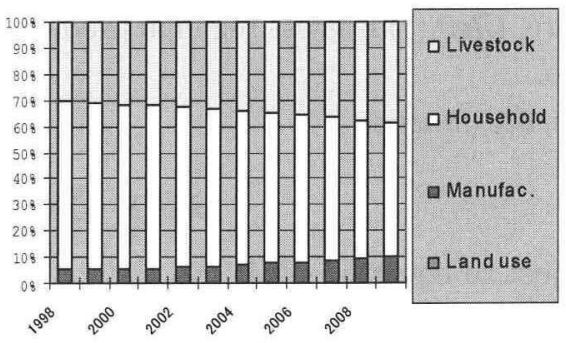

Figure 5 TSS contribution by sectors 


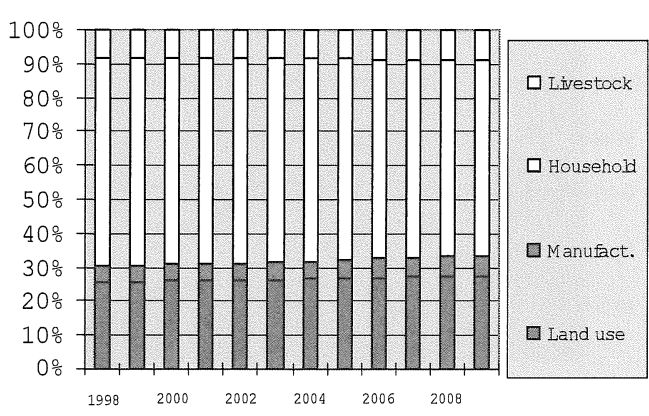

Figure 6 TP contribution by sectors in the basin

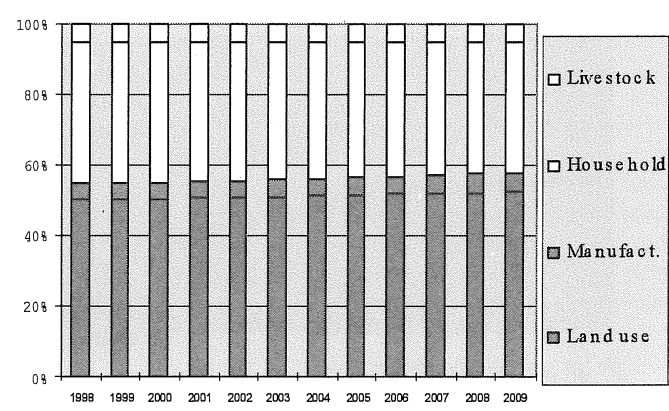

Figure 7 TN contribution by sectors in the basin

Manufacturing and livestock activities are not considerable amount comparing the total land use and household contributions and it is less than $30 \%$ except TSS in the basin. Figure. 5 shows the distribution of TSS by sectors in the basin. Here, land use contribution assumed that is zero because of lack of data and information in the basin as a fact it might contribute considerable amount.

In order to figure out the whole basin structure, it is necessary to analyze in detail sector by sector in each zone and their characteristics on water pollution issues. Therefore, we also specify the model for each sector in each zone as follows;

\subsubsection{Household Pollution}

Household pollution generates from population related to treatment types. Therefore, total population in the initial year of simulation period is classified into 2 categories village and municipality population, then municipality population classified into 4 categories these are population even have no sewerage system, only with sewerage system, pretreatment and biological treatment so as to apply export coefficient and cost of treatment per head in each category.

In Turkey, emission coefficient is estimated $\mathrm{g} / \mathrm{head} / \mathrm{day}$. It means, population connected sewerage system discharge 50-60 g BOD, 80-90 g COD, 70-90 g TSS 10-12 g TN and 3-4 g TP per head/day [14]. Here we assumed the average number of them for example, for BOD is assumed $55 \mathrm{~g} /$ head/day. In the model it is also assumed that the pretreatment category, pollution reduction rate is $20 \%$ for BOD and COD, $45 \%$ for TSS, $7.5 \%$ TN, and $10 \%$ TP. For the biological treatment, the removal rate is $91 \%$ for BOD and COD, $87 \%$ for TSS, $38 \%$ for TN, and $40 \%$ for TP. Biological treatment does not include nutrient removal system as mentioned above consequently, TN and TP removal rate is quite small. These rates are almost the same that treatment plants have been established and operated in Turkey. Cost of treatment for each category is estimated using population data, investment and operational cost for sewerage system, pretreatment and biological treatment that government and/or municipalities have established so far in Turkey and in the basin [12], [19]

The total amount of household pollution and its behavior is shown in Figure 8. The total BOD, COD, and TSS are reduced about 37\%, TN and TP by $12.4 \%$ and $13 \%$ respectively at the end of 2009 in the basin. However, reductions of pollutants are not the same in each 


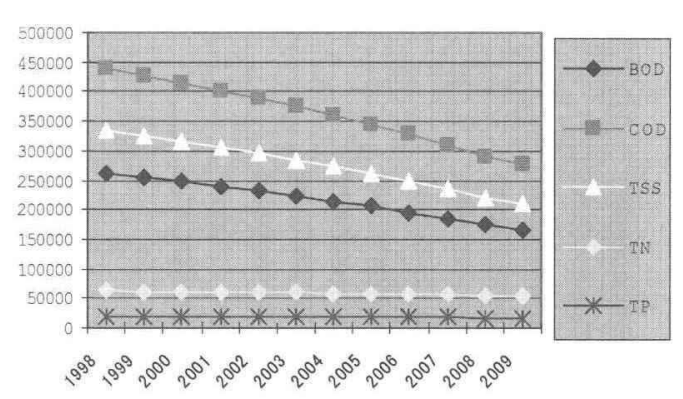

Figure 8 Household pollution in the basin (ton)

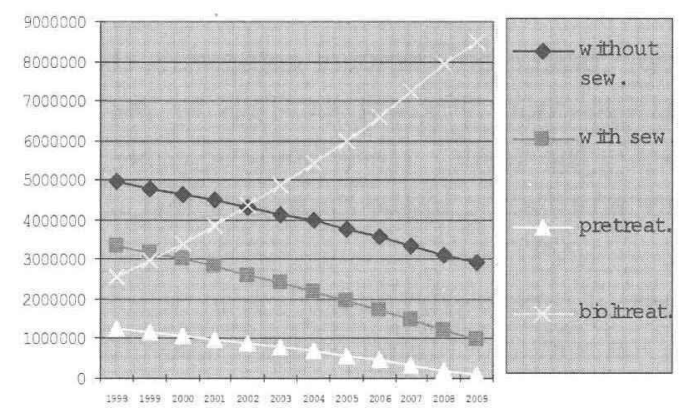

Figure 10 Treated population in the basin

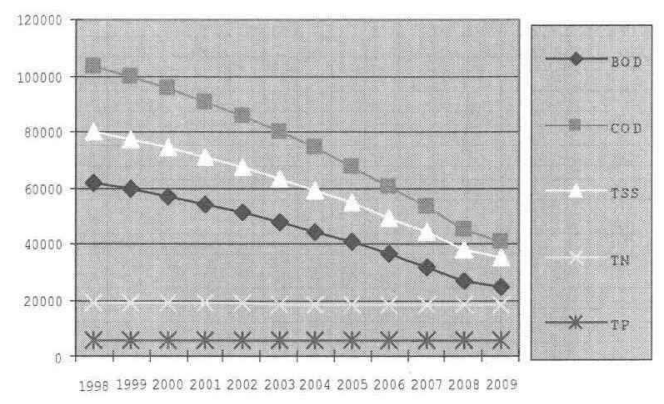

Figure 9 Household pollution in zone 1 (ton)

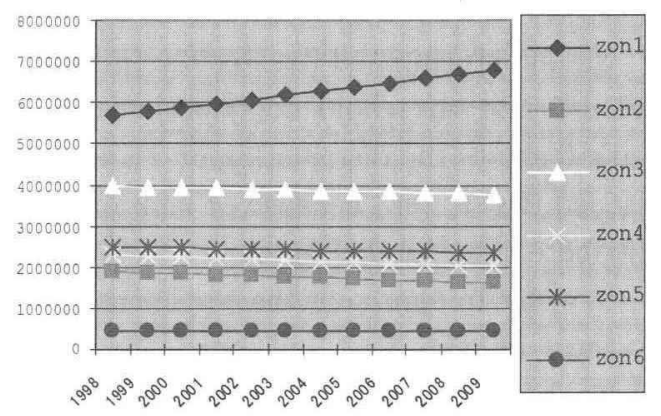

Figure 11 Total population by the time in the basin

zone. For example, in zone 1, BOD and COD reduction is about $60 \%$, TSS $55 \%$, TN, and TP about 5\% shown in Figure 9. This is because of the treatment system, distribution of population in each category and investments for treatment..

In the model, we also specified the relation between treated and untreated population demonstrated in Figure 10, which separated from total population by the time is shown in Figure 11. Treated population increases starting from less than 3 million to 8.5 million at the end of the simulation period means, have received biological treatment. At the same period, the other categories, the number of population decrease from 5 million to 3 million for without sewerage category, 3.4 million to 1 million for sewerage category and more than 1 million pretreatment categories reduced to zero by the time in the basin. It means those reduced categories go to biological treatment categories. Therefore we can easily know that how many people treated from each category and when the untreated population reaches to zero all population is treated and it is not necessary for investment just maintains should be applied.

Treated population is also not the same in each zone. As an example, in zone 1, which is the richest and developed zone in the basin therefore, all population treated at the end of 2010. However, the other zones treatments are not enough to treat all population in the simulation period. For instance, zone 4, 800 thousands people except village population in the same zone have not yet treated at the end of the year 2010

There is also no investment for village population category in the basin because there is no option for treatment. Therefore, according to increasing or decreasing of population by the year the pollution increases or decreases. Contribution of village pollution in zone 1,2 , 


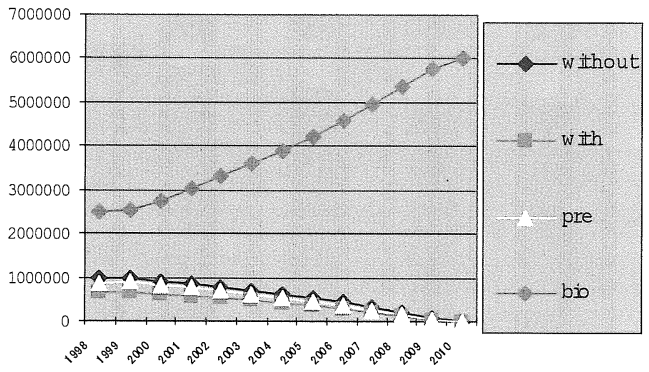

Figure 12 Treated population in zone 1

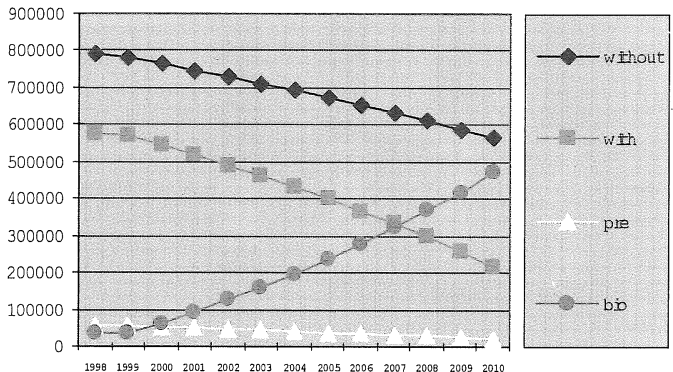

Figure 13 Treated population in zone 4

4, 5 and zone 6 are about 12-15 thousands ton of BOD, 20-25 thousands ton of COD, 11-14 thousands ton of TSS, 2500-3500 ton TN, and 900-1200 ton TP. Zone 3 has the biggest number of village population. Therefore, the contribution is considerable amount such as 20 thousands ton BOD, 35 thousands ton COD, 18 thousands ton TSS, 4.8 thousands ton TN, and 1.5 thousands ton TP flow to water resources.

\subsubsection{Land Use Pollution}

Land use activities are the second biggest factor for all the zones. We classified the land use into 5 categories mentioned in the model. According to monitoring study carried by State Statistic Institute (SIS) in Turkey, land use change by the time is negligible. Pollution from land use is as known non-point source of pollution that it is not easy to find out how much pollution release to the water resources [1], [2], [4]. Furthermore, pollution export rate is also not known in Turkey and in the basin. Therefore, we search studies on agriculture and other land use activities that have similar characteristics with the study area carried by scientists like [4], [15], [16], [25], [30], international organizations [13], [29] and governmental organizations [5], [19], [21], [23]. Then we harmonize and estimate the export coefficient for each land use category. For example, cropland export rate used in the basin is $5.1 \mathrm{~kg} / \mathrm{ha} / \mathrm{y}$ for BOD, $8.6 \mathrm{~kg} / \mathrm{ha} / \mathrm{y}$ for $\mathrm{TN}$, and $1.2 \mathrm{~kg} / \mathrm{ha} / \mathrm{y}$ for $\mathrm{TP}$ that reaches to water resources.

Contribution of land use pollution in terms of pollution parameters illustrates in Figure 14. It is obvious from the figure that the area used as a crop production has the biggest share of pollution in the basin. Crop production itself contributes more than $55 \%$ for all pollutants

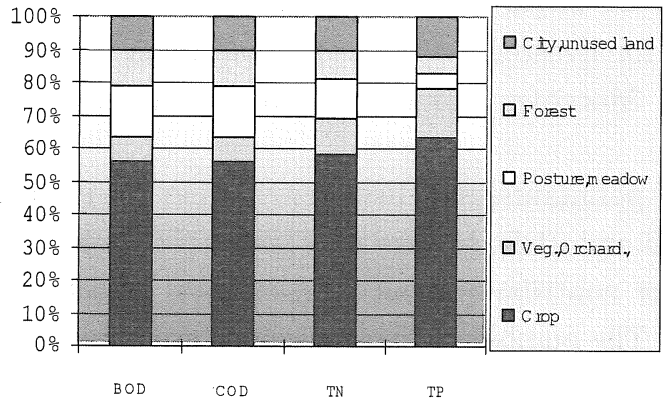

Figure 14 Land use pollution in the basin

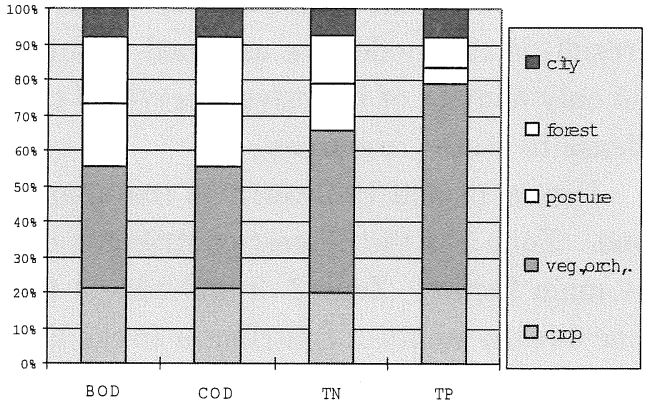

Figure 15 Land use pollution in zone 5 


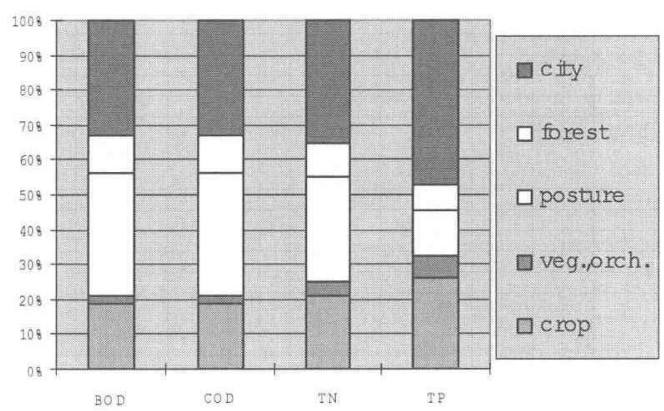

Figure 16 Land use pollution distribution in zone 6

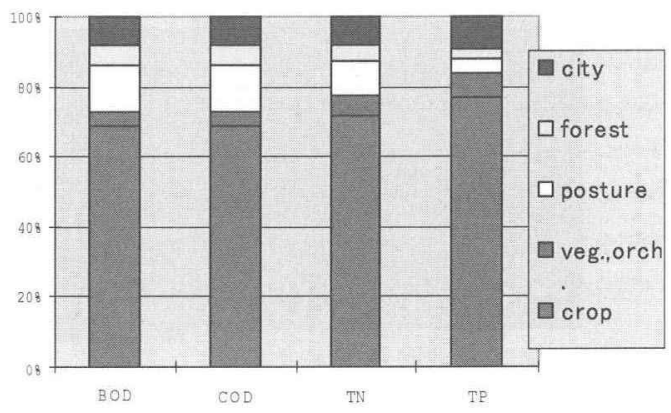

Figure 17 Land use pollution in zone 3

and it reaches $60 \%$ of $\mathrm{BOD}$ and $\mathrm{COD}, 70 \% \mathrm{TN}$, and almost $80 \%$ of TP with vegetablevineyard-orchard category. These two categories are together agriculture activities. The others like forest, posture-meadow, city-unused land contribute about $10 \%$ for BOD, COD and TN. TP contribution from those activities are about $5 \%$ except city area that reaches $11-12 \%$ of total contribution in the basin. In case of the zone 1,2 and zone 4 show the similar characteristics as in the basin mentioned above. However, zone 3, 5 and zone 6 have different kind of land use activities are illustrated in Figure 15, 16 and 17. Zone 3 has the largest agriculture production area particularly cropland. Therefore, it contributes more than $85 \%$ for BOD, COD, TN, and approximately $90 \%$ of total TP. Zone 5 contributes the biggest amount of pollutants from the vegetable-vineyard-orchard category. Zone 6, the cityunused land, and posture-meadow are the dominant contributor means; agriculture lands here is not productive enough and not so big compare the other zones.

\subsubsection{Livestock Pollution}

We estimate the livestock pollution using number of dairy/beef cattle and poultry, concerning the studies on animal rising, production and pollution [5], [13], [30].

In the basin, animal rising is not intensive except poultry. In general, most farmers have a few numbers of cattle and taken to harvested agricultural land, grassland, or posture for grazing every day except winter season and bad weather. Animals spend outside most of the time a day. Therefore, pollution generates from cattle should not be high amount because ; this is actually a king of natural fertilizing separated on the land. Second, the manure that collected by the farmers used as fertilizer on the agricultural land so, pollution from cattle is a part of land use (agriculture) activity that we already assumed load factor for it. As a result, in the model, we assumed load factor for livestock considering poultry as a whole and only number of intensive dairy/beef cattle. Moreover, pollutants from manure storages release to water resources.

Figure 18 and 19 illustrates the amount of pollutants and their distribution from each zone. Zone 3 is the biggest contributor of BOD and COD, In case of TN and TP, zone 2 is the main factor. Zone 2, 3 and zone 4 together contribute about $70 \%$ of total pollutants. Zone 6 is the smallest contributor in the basin. The number of livestock does not change by the time as a considerable amount according to the data [23]. Therefore, amount of pollution by the time is assumed constant and there is no policy measure to mitigate the 


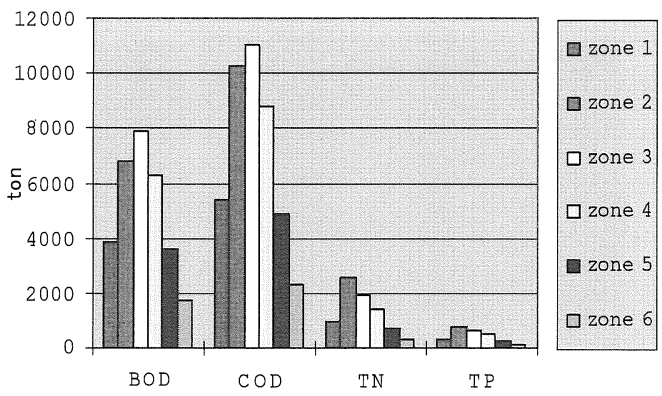

Figure 18 Livestock pollution in the basin

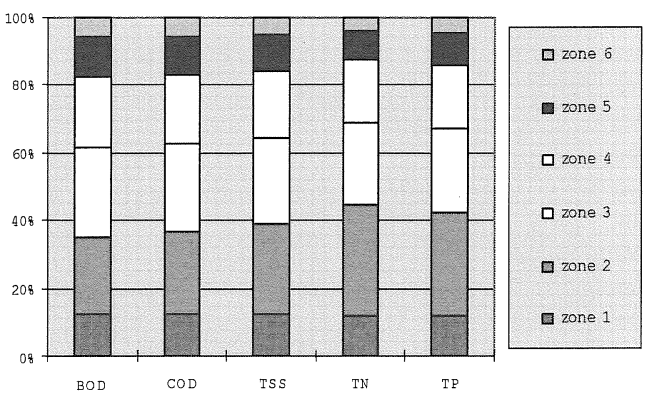

Figure 19 Contribution of livestock pollution by zones

pollution.

\subsubsection{Industrial Source of Pollution}

We classified industries into 27 categories in each zone. The data is used in 1998 as an initial year and 1998 price applied for simulation period. It is assumed that producing per unit of production releases an amount of pollutants. It is of course, each sector's unit of production discharges different amount of pollutants. SIS estimates industrial total load of pollution in Turkey. We convert the total pollution into per unit of production in each sector in each zone including fisheries except agriculture, livestock, and forestry. We also classified each industry in 5 abatement categories mentioned in the model so as to estimate total pollution and treatment cost per unit of production using some assumptions [26], [27] [28] [29] for each treatment category.

The fate of industrial pollution in terms of pollutants is illustrated in Figure 20. Almost all pollutants are increasing $50 \%$ at the end of the simulation year although some of industries have treatment plants. Here we can conduct that most of increasing of pollutants come from some industries that do not have treatment plants or not efficient. Industrial pollution mostly comes from manufacturing sector.

In the model, we introduced all sectors. However, in this paper we show the ones contribute more than $85 \%$ of total industrial pollution in zones. Distributions of pollutants by sectors are not the same in zones. Zone 1 is the biggest producer among the others. The

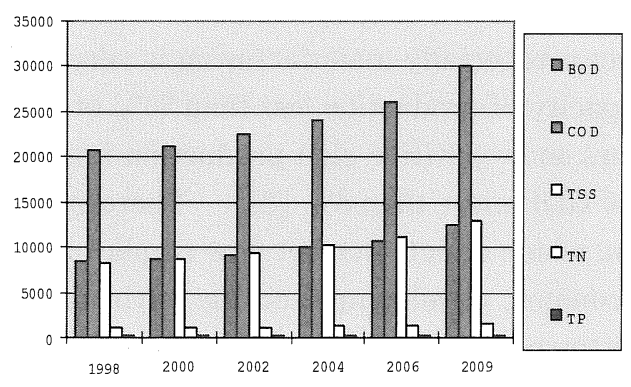

Figure 20 Industrial pollution by year in the basin

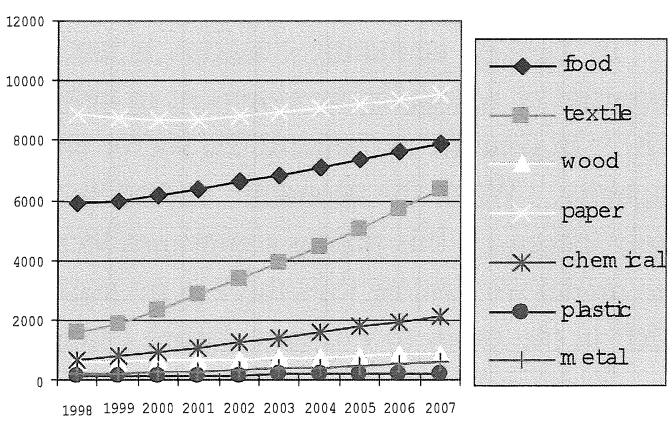

Figure 21 Industrial COD pollution by year in żone 1 


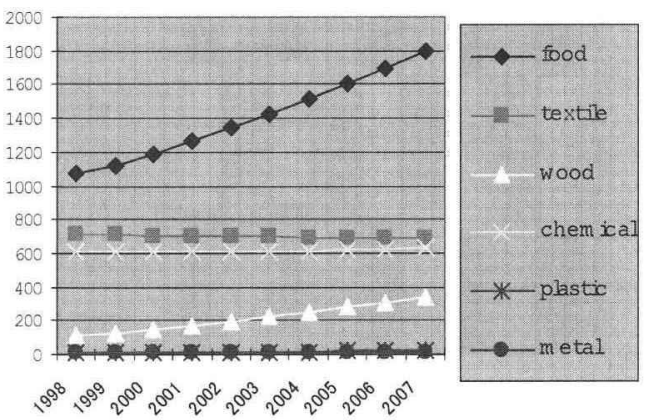

Figure 22 Industrial pollution (COD) distributions in zone 4

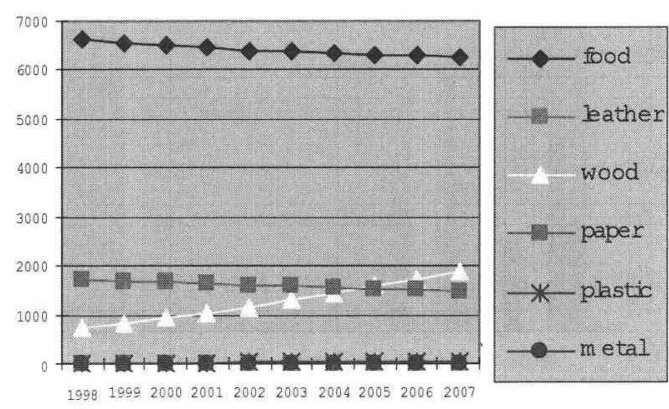

Figure 23 Industrial pollution (COD) by sectors in zone 5

distribution of COD by main sectors in zone 1 is demonstrated in Figure 21. It is clear from the figure that paper industries contribute the biggest amount of COD followed food, textile, chemical, plastic, and other sectors. COD also increase dramatically by sectors particularly textile and food in zone 1 . In case of zone 2, food sector is dominant for contribution of COD and the next are wood, paper, textile, metals, and others. By the time, in zone 2 wood sector' s pollution increases dramatically. However, food and paper, pollution decrease a small amount in the period of simulation. In zone 4, food sector is the biggest polluter, next textile, chemical, plastic, and other sectors.

Pollution (COD) from food sector increases almost two times, next wood industry as illustrated in Figure 22. Another example for zone 5 shown in Figure 23, food sector is again the biggest COD contributor although it is reduced $10 \%$ by the time. As a result, we could emphasize that food, textile, paper, chemical, wood, plastic, and metal are the main sources of manufacturing pollution. BOD and TSS contribution also considerable amount by sectors mentioned above. However, TN and TP pollution are almost zero except particularly food, chemical, textile, non-metal, metal, and machinery respectively.

Fishery means, freshwater fish farming is not a manufacturing sector, but we put into the same category because, we assume that the production is the function of pollution, although there is no option for abatement. Pollution from fish farming in terms of BOD, COD is not large amount. However, TN and TP contribution is highly considerable.

\subsection{Market Flow and GRP}

In Turkey, economic situation is not stable yet and fluctuating by the year. However, potential of economic development in industrial sector especially manufacturing is very high [18]. In general, manufacturing sector uses its capacity of production less than $80 \%$ of total capacity. When the economic and social indicators show positive sign production immediately increases, this makes sometimes increasing of GDP more than $8 \%$ [22]. Therefore, in the model we assume that there is no negative sign, which affects market flow condition and GRP in the basin to estimate future changes of economic development on the environment

In the model, it can be seen capital stock, investment, production, and treatment interrelation with market flow in each zone and sectors. Here we assumed that the investment for treatment which is estimated as a part of total investment in 1998 and this investment will 


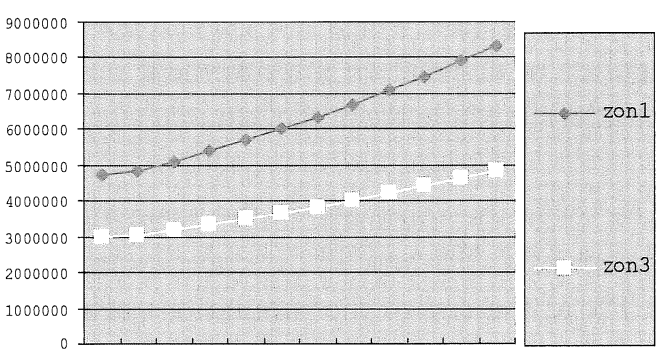

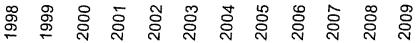

Figure 24 Total GRP in zones by time (billion TL)

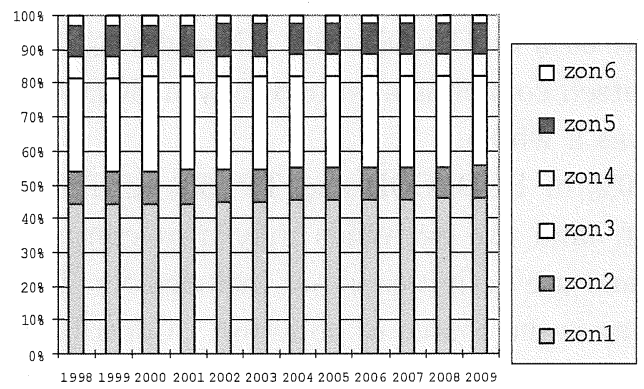

Figure 26 GRP contribution by the zone

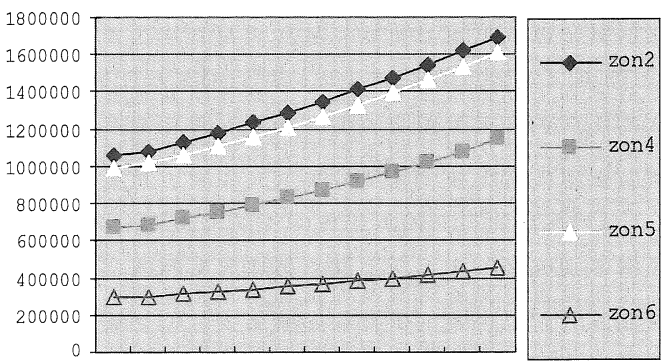

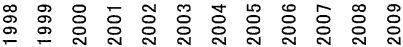

Figure 25 Total GRP in zones by time (billion TL)

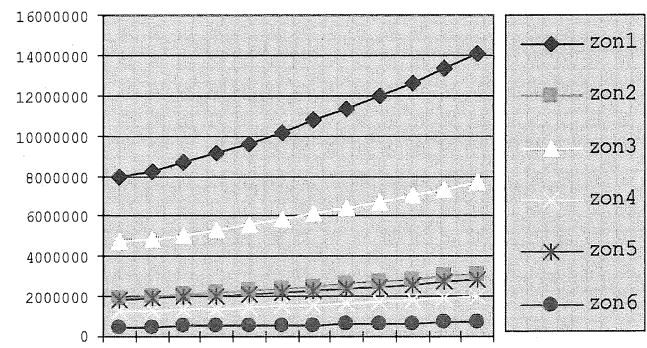

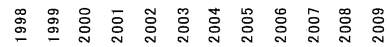

Figure 27 Total production in the basin

increase or decrease in future according to other factors such as production, consumption, investment and capital stock. In case of the GRP in each zone, value added ratio in 1998 is used which is function of output.

Total GRP and contribution from each zone are shown in Figure 24, 25 and 26. It is clear that GRP increases in each zone by the time. Zone 1 has the biggest amount of GRP, it increases $77 \%$ at the end of 2009 , and its contribution is $45 \%$ of total GRP in the basin. Zone 3 is the second zone that GRP increases $64 \%$ and contributes about $27 \%$ of total GRP in the basin. Zone 2 and zone 5 third and fourth biggest zones and GRP increase about 60\% by the time and also their contribution is similar around $10 \%$. Zone 4 and zone 6 together contribute about 10\%, their GRP increase $70 \%$ and $54 \%$ respectively by the simulation period. Zone 6 is the poorest and undeveloped basin comparing the others.

As another example, total production is also gives similar result as illustrated in Figure 27. Zone 1 and zone 3, again are the biggest zones, the next is zone 2, 5, 4 and zone 6 . We can conduct that there is a linear relation between GRP, production, investment and consumption in the basin by simulation period

\section{Conclusion}

We can conclude that the modeling of the ecosystem and economic structure based on available data and some assumptions is an appropriate way in providing valuable information related pollution, sectors' contributions and relation with economic indicators such as production, investment etc. in the basin system. Here, with the simulation result, we find out 
current environmental and economic state and future changes, which are very important to be able to formulate and introduce an optimal policy to achieve an improvement on water quality with considerable economic growth. Considering whole basin the summary of result, we figure out as follows:

1-Domestic sources of pollution is the main factor in the zones and in the basin although it is reduced by $37 \%$ for BOD, COD, TSS and about $13 \% \mathrm{TN}$ and TP. It contributes about $50 \% \mathrm{BOD}, \mathrm{COD}$, around $55 \%$ of $\mathrm{TP}$ and $40 \%$ of $\mathrm{TN}$ at the end of the simulation period. It means the investment for household treatment is not sufficient because half of the population still do not receive any treatment. Furthermore, the cost of investment is very high because it also includes the cost of sewerage system, which is necessary to establish the treatment plant. Moreover, existing treatment plants are not adequate regarding TN and TP.

2-Land use activities are the second biggest contributors in the basin and in zones particularly agriculture activities which contribute $60 \% \mathrm{BOD}, \mathrm{COD}, 70 \% \mathrm{TN}$ and $80 \% \mathrm{TP}$ of the total land use origin of pollutants. Land use itself contributes around 25\% of BOD, COD, and $\mathrm{TP}$ and more than $50 \%$ of $\mathrm{TN}$ in the basin as a whole.

3 -Livestock in the basin contribute about 10\% of BOD, COD and TP, $5 \%$ of TN and about $30 \%$ of TSS. TSS seems high. In fact, land use activities may also contribute considerable amount of TSS but in this model land use activities is not included for TSS.

4-Industrial sector, particularly manufacturing is the source of pollution. Contribution from manufacturing is about $15 \%$ of $\mathrm{BOD}, 20 \%$ of COD, $10 \%$ of TSS and about $5 \%$ of TN and TP. at the end of the simulation period. Here, the main problem is pollution from manufacturing sectors increase about $50 \%$ for all the pollutants from 1998 to 2009 . Second, distribution of sectors and their contributions in each zone are quite different. In general, food, textile, paper and chemical, industries are the main polluting industries in the basin.

5 -According to simulation result GRP increase considerable amount due to increase of production, investment etc. In fact, this is rational considering current dynamic economic state in Turkey and in the basin. However, pollution also increases although it is less than increasing of GRP by the time indicates that investments for treatment facilities are not adequate to reduce the total pollution in acceptable level. Here, one of the main interrelations is investments for treatment with investments for production. Sum of these two investments is total investment for each sector in each zone. Investments for production increase dramatically by the year but investments for treatment do not increase as much investments for production as. Therefore, most investments turn to production, increase output and other indicators including GRP because investments for treatment as part of the total investment do not influence considerable amount on investments for production and reducing the pollutants.

As a result, we would emphasize that the existing policy is not sufficient to reduce the pollutants in the future. It is clear that some policy measures should be applied on the basin that gives less harm to environment. As further stages of this paper, number of policy measures will be introduced. In general, we could propose some policy instruments that would be used in the model as follows:

Regarding household wastewater, the types of treatment facility will be chosen considering some factors such as scale of settlement, availability, and characteristic of land, cost, etc. 
For example, biological treatment is efficient in reducing BOD, COD, and TSS but it is not sufficient for TN and TP treatment. Therefore, it is necessary to introduce nutrient removal system with the treatment facility. For villages which are small settlements require some specific treatment techniques that sufficiently applicable in the basin.

Industrial activities since we have detailed classification of sectors, it is easy to introduce a specific treatment technique for each specified sector. For instance, under the textile sector there are three sectors, which are wearing-dressing, dying, and leather. Textile for just cotton production or wearing-dressing biological treatment is sufficient. However, for dying and leather sector chemical treatment is also necessary. It is also known that biological treatment is sufficient for food sector while chemical industry may need coagulation with chemical beside activated sludge system.

Although land use activities and livestock are the most difficult issue to control first, we would introduce in the model production of agriculture and livestock related pollution in order to find out change of production impact on pollution. Then it would be applied some practices like land use conversion, adequate cultivation, irrigation and fertilization techniques, crop rotation and planting systems etc. Besides, protecting the forestry, grassland, and wetland are some other options.

We would introduce budget balance for the government and municipality in the model to analyze the tax and subsidy systems and study possibility of optimal utilization of existing tax and subsidy. Furthermore, user charge, quotas, or other economic instruments might be introduced to make a balance between economic growth and environmental media.

\section{References}

[1] Arheimer, B., Brandit, M., "Watershed Modeling of Non-point Nitrogen Losses from Arable Land to the Swedish coast in 1984 and 1994" Ecological Engineering, Vol. 14 pp. 389-404, 2000

[2] Baginska, B., et al., "Nutrient Export from rural in the Hawkesbury-Nepean Catchment" Proceeding of 9. th Australian Agronomy conference, Wagga wagga, 1998,

[ 3 ] BSEP. Black Sea Environmental Program, "Saving the Black Sea", Official Newsletter of the GEF, Issue 1, 1994.

[4 ] Beler Baykal, B et. al., "Effect and Control of Pollution in Catchment Area of Lake Sapanca, Turkey" Environmental Management, Vol. 22, No. 3 pp. 407-414

[5] DEFRA, Department for Environment Food \& Rural Affairs. Report, "Agriculture and Water: a Diffuse Pollution Review" 2002, England

[6] GEF, BSEP, Black Sea Transboundary Diagnostic Analysis, United Nations Publications, No E.97. III. B.15. Black Sea Environmental Program, Istanbul, 1997.

[7] GEF Global Environmental Facility, Program Coordination Unit, Black Sea Environmental Program, Istanbul, 1996

[ 8 ] Higano, Y., Sawada, T., "The Dynamic Policy to Improve the Water Quality of Lake Kasumigaura", Studies in Regional Science, Vol. 26, No.1, 1997, pp. 75-86.

[ 9 ] Higano, Y., Yoneta, A., "Economical Policies to Relieve Contamination of Lake Kasumigaura", Studies in Regional Science, Vol.29, No. 3, 1998, pp. 205-218.

[10] LINDO systems Inc., "Lingo user guide", 1415, north Dayton Street. Chicago, Illions 60622

[11] Ministry of Energy and Natural Resources, General Directorate of Electricity Works, Monthly Average Water Flow 1935-1995, Ankara, 2000.

[12] Municipality of Ankara, "Ankara central Wastewater treatment Plant; Cost, Treatment Capacity 
and Properties" Report, 2000. General Directorate of Wastewater and Sewerage Systems, Ankara (In Turkish)

[13] OECD "Environmental Indicators towards Sustainable Development" OECD Publication 2. p. 127, 1998 France

[14] Province Bank, "Wastewater treatment system process regulation" 1990, Turkey.

[15] Ramos, C., Agut, A., Lidon, A.L., Nitrate leaching in important crops of the Valencian Community Region (Spain) Environmental Pollution, Vol. 118, pp. 215-223, 2002

[16] Skop, E., Schou, J>S., "Modeling the Effect of Agricultural Production. An integrated Economic and Environmental Analysis Using Farm Account Statistics and GIS". Ecological Economics, Vol. 29, pp, 427-442. 1999

[17] State Hydraulic Works, Research Planning and Coordination Department, Statistic Bulletin with Maps-1999, No. 991, Ankara, 2001

[18] State Planning Organizations, "Industrial Politics: Special Commission Report, Eighth. Five year Development Plan, DPT, 2529 OIK, 545, 2000 Turkey (In Turkish)

[19] State Planning Organizations, "Drinking and Wastewater Treatments Systems and Solid Waste Control" Special Commission Report, Eighth. Five year Development Plan, DPT, 2503, OIK, 545, 2000 Turkey (In Turkish)

[20] State Institute of Statistic, Input-Output Structure of Turkish Economy, SIS pub. 1996, Turkey

[21] State Institute of Statistic, River Basin Statistics, 1996, No. 2488, SIS press, 2001, Ankara. (In Turkish and English)

[22] State Institute of Statistic, "Economic and Social Indicators" Ankara, Turkey. SIS press, 2000 (In Turkish, English)

[23] State Institute of Statistic, "Agricultural structure (price, production, value)" No 2457, 1999, Turkey

[20] Ulger, S., Higano, Y., "A Preliminary Study to Improve the Water Quality in the Black Sea: Turkish Black Sea Basin", Studies in Regional Science, The Japan Section of the RSAI Vol. 32, No. 1, 2002; pp. 353-367.

[25] Vanni, M. J., et. al., "Dissolved and Particulate Nutrient Flux from three adjacent agricultural watersheds: A five year Study” Biogeochemistry, Vol. 54, pp. 85-114, 2001

[26] World Bank, "Water Pollution Abatement by Chinese industry, Cost Estimates and Policy Implications" Policy Research Working Paper, WPS 1630, 1996.

[27] World Bank, "Pollution Charge Community Pressure and Abatement Cost : an Analysis of Chinese Industries". Development Research Group, January 2000.

[28] World Bank, "Industrial Pollution Projection System (IPPS)" Policy Research Working Paper, 1431 Part 1, 1994

[29] WHO, World Health Organization, Assessment of Sources of Air, Water, and Land Pollution, Part I, Geneva, 1993.

[30] Wit, M., Bendoricchio, G., "Nutrient Fluxes in the Po Basin" The Science of Total Environment, Vol. 273, pp. 147-161, 2001 